\section{Dose intensity for conditioning in allogeneic hematopoietic cell transplantation: can we recommend "when and for whom" in 2021?}

\author{
Nico Gagelmann and Nicolaus Kröger \\ Department of Stem Cell Transplantation, University Medical Center Hamburg- \\ Eppendorf, Hamburg, Germany
}

\section{ABSTRACT}

Volume 106(7):1794-1804

\section{Correspondence:}

NICOLAUS KRÖGER

nkroeger@uke.uni-hamburg.de

Received: December 1, 2020.

Accepted: February 2, 2021.

Pre-published: March 18, 2021.

https://doi.org/10.3324/haematol.2020.268839

(C)2021 Ferrata Storti Foundation

Material published in Haematologica is covered by copyright. All rights are reserved to the Ferrata Storti Foundation. Use of published material is allowed under the following terms and conditions:

https://creativecommons.org//icenses/by-nc/4.0/legalcode. Copies of published material are allowed for personal or internal use. Sharing published material for non-commercial purposes is subject to the following conditions:

https://creativecommons.org/licenses/by-nc/4.0/legalcode, sect. 3. Reproducing and sharing published material for commercial purposes is not allowed without permission in writing from the publisher. llogeneic hematopoietic stem-cell transplantation is a potentially curative therapy for various hematologic diseases. An essential component of this procedure is the pre-transplant conditioning regimen, which should facilitate engraftment and reduce or eliminate tumor cells. The recognition of the substantial association of a graft-versus-tumor effect and the high toxicity of the commonly used conditioning regimen led to the introduction of more differentiated intensity strategies, with the aim of making hematopoietic stem-cell transplantation less toxic and safer, and thus more applicable to broader populations such as older or unfit patients. In general, prospective and retrospective studies suggest a correlation between increasing intensity and nonrelapse mortality and an inverse correlation with relapse incidence. In this review, we will summarize traditional and updated definitions for conditioning intensity strategies and the landscape of comparative prospective and retrospective studies, which may help to find the balance between the risk of non-relapse mortality and relapse. We will try to underscore the caveats regarding these definitions and analyses, by missing complex differences between intensity and toxicity as well as the broad influences of other factors in the transplantation procedure. We will summarize evidence regarding several confounders which may influence decisions when selecting the intensity of the conditioning regimen for any given patient, according to the individual risk of relapse and non-relapse mortality.

\section{Categorized traditional and updated definitions}

Although full consensus has not been reached within the hematopoietic stemcell transplantation (HSCT) community, ${ }^{1}$ conditioning regimens have usually been classified as high-dose (MAC), reduced-intensity (RIC), and non-myeloablative (NMA). ${ }^{2}$ Based on these criteria, ${ }^{3}$ myeloablative, or "high-dose" regimens, consisting of alkylating agents with or without total body irradiation (TBI), are expected to ablate marrow hematopoiesis, not allowing autologous hematologic recovery. In contrast, NMA regimens, although causing minimal cytopenia, do not require stem cell support. ${ }^{4}$ Regimens that do not fit the definition of MAC or NMA are classified as RIC regimens: they result in potentially prolonged cytopenia, and they require hematopoietic stem cell support. What differentiates RIC regimens from myeloablative regimens is that the dose of alkylating agents or TBI is generally reduced by $\geq 30 \%$. Notably, "intensity" was defined here on the basis of grade of reversible and irreversible myelotoxicity rather than of non-hematologic toxicity. Despite this imprecise definition of intensity and toxicity and the lack of their universality (agreement for these criteria was found in $<75 \%$ ), this classification has served as a clinical tool and enabled some, although still limited, comparability with registries such as that of the European Society for Blood and Marrow Transplantation (EBMT)..$^{5-7}$

It is important to recognize, however, that regimens classified as MAC or RIC can vary substantially, regarding intensity and toxicity, which is also reflected by so-called "sequential" strategies; $;$, and the rigidity of this scheme further impeded 
the inclusion of new regimens showing reduced nonhematologic toxicity and different safety profiles in general..$^{10}$ Moreover, this classification ignores the additional intensity of purine analogs used for immune-ablation ${ }^{11}$ or of disease-specific drugs used to achieve reduction in relapse risk. Thus, in literature less well-defined terms, such as "reduced toxicity", ${ }^{12}$ "hyper-intensive"13 or "augmented reduced intensity" are now more commonly used. ${ }^{14}$ To address this increasing variability, the EBMT has recently proposed an updated refined classification, assigning intensity weight scores for frequently used conditioning regimen components in relation to their prognostic value for non-relapse mortality (NRM); and using their sum to generate a transplant conditioning intensity score. This also categorized classification showed only slightly improved discrimination for the outcome of NRM, while discrimination and thus prognostic utility with respect to the outcome of relapse were comparable to the previous dichotomized RIC/MAC classification. $^{15}$

\section{Prospective randomized studies with different dose intensities}

Prospective randomized studies comparing different condition regimen intensities exist only for acute myeloid leukemia (AML) and myelodysplastic syndrome (MDS) (including very few patients with chronic myeloid leukemia; see Table 1), while no prospective randomized studies exist for other hematologic malignancies includ- ing non-Hodgkin lymphoma, Hodgkin lymphoma and multiple myeloma.

\section{Toxicity-reduced myeloablative conditioning versus myeloablative conditioning}

The first trial of toxicity-reduced MAC versus MAC was a randomized phase III trial by Bornhäuser et al. in 195 patients (median age 44 years) with intermediate- or high-risk AML in first complete remission. ${ }^{16}$ Treatment in the lower intensity arm consisted of a lower dose of TBI (800 cGy) plus fludarabine which was compared to a standard MAC approach of cyclophosphamide-TBI (1200 cGy). Although the study was concluded early because of slow accrual of patients, outcomes were not significantly different with regards to NRM, cumulative incidence of relapse, and survival, with these findings being confirmed in a long-term follow-up report. ${ }^{17}$ Interestingly, severe mucositis and in-hospital mortality were less frequent in the RIC group, leading to the conclusion that RIC regimens lessened the toxic effects of transplantation, and the short-term mortality at 1 year was lower in the RIC group. An age limit of 60 years may impede the interpretation of the findings. In contrast, these results suggest that perhaps RIC regimens should be used preferentially in patients $<60$ years old with AML in first complete remission. Aside from this, the RIC regimen of TBI 800 cGy is, according to the current definition, still a MAC regimen .

Another attempt to reduce intensity and toxicity without losing myeloablative intensity of the conditioning regimen was made by replacing cyclophosphamide with

Table 1. Characteristics and results of prospective randomized trials comparing different intensities and toxicity of conditioning regimens.

\begin{tabular}{|c|c|c|c|c|c|c|c|}
\hline Trial & Population & Reg & imen & $\begin{array}{c}\text { RFS } \\
\%(P)\end{array}$ & $\begin{array}{l}\text { Relapse } \\
\%(P)\end{array}$ & $\begin{array}{l}\text { NRM } \\
\%(P)\end{array}$ & $\begin{array}{c}\text { OS } \\
\%(P)\end{array}$ \\
\hline \multicolumn{8}{|c|}{ Toxicity reduced MAC $v s$. MAC or RIC } \\
\hline Rambaldi et $a l^{20}$ & $\begin{array}{l}\text { AML } \\
\text { Age }>40 y\end{array}$ & BuFlu (MAC) & BuCy (MAC) & $\begin{array}{l}40 \text { vs. } 47 \\
\text { (ns) }\end{array}$ & $\begin{array}{l}24 \text { vs. } 21 \\
\text { (ns) }\end{array}$ & $\begin{array}{c}8 \text { vs. } 18 \\
(0.03)\end{array}$ & $\begin{array}{l}27 \text { vs. } 35 \\
\text { (ns) }\end{array}$ \\
\hline Bornhäuser et al. ${ }^{16}$ & $\begin{array}{l}\text { AML CR1 } \\
\text { Age } 18-60 \text { y } \\
\text { IR/HR cytogenetics }\end{array}$ & 8 GyTBIFlu (MAC) & 12 GyTBI/Cy (MAC) & $\begin{array}{l}58 \text { vs. } 56 \\
(\mathrm{~ns})\end{array}$ & $\begin{array}{l}28 \text { vs. } 26 \\
\text { (ns) }\end{array}$ & $\begin{array}{l}13 \text { vs. } 18 \\
\text { (ns) }\end{array}$ & $\begin{array}{l}61 \text { vs. } 58 \\
\text { (ns) }\end{array}$ \\
\hline Beelen et $_{\text {al. }}{ }^{24}$ & $\begin{array}{l}\text { AML/MDS } \\
\text { Age } \geq 50 \text { y and/or } \\
\mathrm{CI}>2 / \mathrm{KPS}>60 \%\end{array}$ & TreoFlu (MAC) & BuFlu (RIC) & $\begin{array}{l}64 \text { vs. } 50 \\
(0.001)\end{array}$ & $\begin{array}{l}25 \text { vs. } 23 \\
\text { (ns) }\end{array}$ & $\begin{array}{c}11 \text { vs. } 23 \\
(0.05)\end{array}$ & $\begin{array}{c}71 \text { vs. } 56 \\
(0.01)\end{array}$ \\
\hline \multicolumn{8}{|l|}{ RIC vs. NMA } \\
\hline Blaise et $a .^{2}$ & $\begin{array}{l}\text { Hematologic } \\
\text { malignancies }\end{array}$ & BuFlu (RIC) & FluTBI (NMA) & $\begin{array}{l}35 \text { vs. } 23 \\
\text { (ns) }\end{array}$ & $\begin{array}{c}27 \text { vs. } 54 \\
(<0.01)\end{array}$ & $\begin{array}{c}38 \text { vs. } 22 \\
(0.03)\end{array}$ & $\begin{array}{l}41 \text { vs. } 41 \\
\text { (ns) }\end{array}$ \\
\hline \multicolumn{8}{|l|}{ RIC vs. MAC } \\
\hline Ringdén et al. ${ }^{90}$ & $\begin{array}{l}\mathrm{AML} / \mathrm{CML} \\
\text { Age } \leq 60 \text { y }\end{array}$ & $\begin{array}{c}\text { BuFlu (RIC) } \\
\text { incl } n=4 \text { CML (NMA) }\end{array}$ & $\mathrm{BuCy}(\mathrm{MAC})$ & NR & $\begin{array}{l}12 \text { vs. } 35 \\
\text { (ns) }\end{array}$ & $\begin{array}{l}11 \text { vs. } 11 \\
\quad(\mathrm{~ns})\end{array}$ & $\begin{array}{l}76 \text { vs. } 62 \\
\text { (ns) }\end{array}$ \\
\hline Scott et al. ${ }^{26}$ & $\begin{array}{l}\text { AML/MDS in CR } \\
\text { Age } 18-65 \text { y }\end{array}$ & $\begin{array}{l}\text { BuFlu; FluMel } \\
\text { (RIC) }\end{array}$ & $\begin{array}{l}\text { BuFlu; BuCy; } \\
\text { TBICy (MAC) }\end{array}$ & $\begin{array}{l}47 \text { vs. } 68 \\
(<0.01)\end{array}$ & $\begin{array}{l}48 \text { vs. } 14 \\
(<0.001)\end{array}$ & $\begin{array}{l}4 \text { vs. } 16 \\
(<0.01)\end{array}$ & $\begin{array}{l}78 \text { vs. } 68 \\
(0.07)\end{array}$ \\
\hline Kröger et al..$^{25}$ & $\begin{array}{l}\text { MDS/sAML } \\
\text { Age 18-60 y UD } \\
\text { Age 18-65 RD }\end{array}$ & BuFlu (RIC) & BuCy (MAC) & $\begin{array}{l}62 \text { vs. } 58 \\
\text { (ns) }\end{array}$ & $\begin{array}{l}17 \text { vs. } 15 \\
\text { (ns) }\end{array}$ & $\begin{array}{l}17 \text { vs. } 25 \\
\text { (ns) }\end{array}$ & $\begin{array}{c}76 \text { vs. } 63 \\
(0.08)\end{array}$ \\
\hline \multicolumn{8}{|c|}{ RIC $v s$. sequential RIC } \\
\hline Craddock et al..$^{14}$ & $\begin{array}{l}\text { AML/MDS } \\
\text { Age } 18-75 \text { y }\end{array}$ & $\begin{array}{l}\text { FLAMSA-Bu } \\
\text { (seq RIC) }\end{array}$ & $\begin{array}{c}\text { Bu/Flu or } \\
\text { Mel/Flu (RIC) }\end{array}$ & $\begin{array}{l}54 \text { us. } 49 \\
\text { (ns) }\end{array}$ & $\begin{array}{l}27 \text { vs. } 30 \\
\text { (ns) }\end{array}$ & $\begin{array}{l}21 \text { vs. } 17 \\
\text { (ns) }\end{array}$ & $\begin{array}{c}61 \text { vs. } 59 \\
\text { (ns) }\end{array}$ \\
\hline
\end{tabular}

RIC: reduced intensity conditioning; MAC: myeloablative conditioning; NMA: nonmyeloablative; RFS: relapse-free survival; NRM: non-relapse mortality; OS: overall survival; (s)AML: (secondary) acute myeloid leukemia; CML: chronic myeloid leukemia; CR: complete remission; Cy: cyclophosphamide; Treo: treosulfan; Flu: fludarabine; TBI: total body irradiation; Bu: busulfan; IR: intermediate-risk; HR: high-risk; Mel: melphalan; MDS: myelodysplastic syndrome; UD: unrelated donor; RD: related donor; ns: not significant; y: years; CI: comorbidity index; KPS: Karnofsky performance status; NR: not reported; seq: sequential. 
a less toxic immunosuppressive agent, fludarabine. ${ }^{18,19}$ The important prospective randomized study by Rambaldi et al. comparing busulfan-fludarabine conditioning versus busulfan-cyclophosphamide in patients $>40$ years of age with AML showed significantly reduced 1year transplant-related mortality ( $8 \%$ vs. $17 \%){ }^{20}$ Importantly, the comparison showed reduced NRM specifically for patients with a higher comorbidity index and busulfan-fludarabine conditioning, as well as in patients in first complete remission. Adverse event rates were similar in the two groups, except for organ-failure, which was more frequent in the group treated with cyclophosphamide.

Another option to maintain myeloablation, according to the given definition, and immunosuppression but also to reduce non-hematologic toxicity was investigated by replacing busulfan by the alkylator treosulfan, ${ }^{21}$ which exhibits low inter- and intra-patient variability without the need for dose adjustments. ${ }^{22,23}$ A recent prospective randomized trial by Beelen et al. in older ( $\geq 50$ years) and/or comorbid AML/MDS patients randomly assigned patients to receive either intravenous $3 \times 10 \mathrm{~g} / \mathrm{m}^{2}$ treosulfan or reduced intensity busulfan. The initial treosulfan dose of $14 \mathrm{~g} / \mathrm{m}^{2}$ daily was changed due to safety concerns. ${ }^{24}$ Both groups received $30 \mathrm{mg} / \mathrm{m}^{2}$ intravenous fludarabine. Overall, the 2 -year event-free survival rate was $64 \%$ in the treosulfan group and $50 \%$ in the busulfan group, but differences were most pronounced in the subgroup of patients $\geq 50$ years receiving matched unrelated HSCT, whereas there was not a significant difference among patients with a comorbidity index of $\geq 2$. Notably, despite higher intensity, the survival benefit of treosulfan was caused by a higher NRM in the busulfan group which did, however, appear somewhat higher than previously reported. ${ }^{25,26}$

\section{Reduced intensity conditioning versus myeloablative conditioning}

The BMT-CTN study reported by Scott et al. ${ }^{26}$ prospectively compared RIC versus MAC approaches in AML and MDS. In order to have more flexibility, transplant physicians had some choice of preparative approaches. The study design allowed higher-dose busulfan $(12.8 \mathrm{mg} / \mathrm{kg}$ intravenously) with fludarabine or busulfan with cyclophosphamide along with cyclophosphamide-TBI in the MAC arm and lower-dose busulfan ( $8 \mathrm{mg} / \mathrm{kg}$ intravenously) with fludarabine or fludarabine with melphalan in the RIC arm. Enrollment was more rapid and accured 272 patients with AML/MDS patients aged 18-65 years with a comorbidity index $<5$ and $<5 \%$ marrow myeloblasts prior to matched-related or unrelated donor HSCT. The study was closed early because of the finding of superior relapse-free survival in the MAC arm. This study clearly demonstrated that myeloablative busulfan regimens resulted in a significantly improved relapse-free survival (despite a higher NRM rate) and in a significantly lower relapse incidence than the lower-dose busulfan/fludarabine RIC arm. The main cause of death in the MAC arm was graft-versus-host disease (GvHD) (50\%), as compared to relapse (86\%) in the RIC arm. The ability to perform subgroup analyses was limited by the early closure. Nevertheless, these analyses showed survival benefit for MAC for AML patients, high-risk patients and patients with a comorbidity index of 0 .

The EBMT RICMAC triall ${ }^{25}$ prospectively addressed this issue in patients with MDS or secondary AML. The patients included in this trial had to be 18-60 years for those with unrelated donors and 18-65 years for those with related donors. Eighty-five percent of chemotherapies before transplantation were administered in advanced MDS (chronic myelomonocytic leukemia, refractory anemia with excess of blasts, and secondary AML) to reduce the number of blasts. Regimens were busulfan (16 mg/kg orally or $12.8 \mathrm{mg} / \mathrm{kg}$ intravenously) and cyclophosphamide $(120 \mathrm{mg} / \mathrm{kg}$ ) for MAC and busulfan $(8 \mathrm{mg} / \mathrm{kg}$ orally or $6.4 \mathrm{mg} / \mathrm{kg}$ intravenously) and fludarabine $\left(150 \mathrm{mg} / \mathrm{m}^{2}\right)$ for RIC. The trial also accrued slowly, assigning 129 patients, and was closed early after calculations suggested enough power to address the primary aim of determining differences in NRM. The trial showed similar 2-year incidences of relapse, relapse-free survival, and overall survival. Short-term NRM, at 1 year, was also similar but was much lower than predicted. In the multivariable model of NRM, an interaction was found between conditioning intensity and cytogenetics, which led to a subgroup analysis stratified by cytogenetic risk group. In the low-risk cytogenetic group, lower performance status was associated with higher NRM, while the comparison of conditioning intensities showed lower NRM after RIC in this risk group. In the intermediate- and high-risk cytogenetic groups, RIC resulted in a higher NRM rate.

\section{Reduced intensity conditioning versus sequential reduced intensity conditioning}

More recently, Craddock et al. compared, in a prospective, randomized fashion, a sequential transplant regimen with fludarabine-amsacrine-cytarabine followed by busulfan "augmented" RIC to a fludarabine-based RIC in high-risk AML and MDS and did not find any statistically significant difference in therapy-related mortality, relapse or overall survival between the two groups. ${ }^{14}$

\section{Reduced intensity conditioning versus non-myeloablative conditioning}

A further reduction of intensity and toxicity was introduced by a non-myeloablative regimen with only 2 Gy TBI and fludarabine. A prospective randomized study reported by Blaise et al. compared a 2 Gy TBI-based NMA regimen with a busulfan-fludarabine-based RIC regimen. ${ }^{27}$ The incidence of grade $2-4$ acute GvHD was $47 \%$ in the RIC group versus $27 \%$ in the group given NMA conditioning, with no difference in chronic GvHD. The RIC group showed a lower relapse rate (27\% vs. 54\%), while the NRM rate was higher (38\% vs. $22 \%)$. At 5 years, the overall survival rates were identical (41\%).

\section{Evidence summary}

In summary, prospective studies in AML/MDS show a challenging landscape of evidence. No superiority for any arm regarding relapse or NRM was found for AML patients with intermediate-/high-risk cytogenetics and $\leq 60$ years or $\mathrm{MDS} /$ secondary AML patients, ${ }^{16,25}$ with a trend towards better overall survival after RIC in the trial by Kröger et al. ${ }^{25}$ In contrast, Scott et al. ${ }^{26}$ showed a clearly reduced risk of relapse and better overall survival for MAC, despite higher NRM in AML/MDS patients. Intensifying RIC by administering sequential RIC did not improve outcome compared to conventional RIC in high-risk AML/MDS. ${ }^{14}$

Meta-analyses summarizing findings from the afore- 
mentioned randomized trials have been published but are limited by the heterogeneous characteristics across the trials. ${ }^{28,29}$ In conclusion, for AML and MDS, the overall quality of evidence for the optimal conditioning intensity is low. For higher-risk patients, MAC appeared to provide some benefit. ${ }^{29}$ However, in the current setting, only data synthesis on the level of individual patient data may be of additional value.

\section{Retrospective studies in acute myeloid leukemia/myelodysplastic syndromes}

The wide basis for current clinical consensus statements with regards to conditioning intensity in AML/MDS draws on data from retrospective comparisons (Table 2). The first study to compare outcomes of conventional MAC versus RIC was from an EMBT registry study that looked at 722 patients with AML $>50$ years. ${ }^{30}$ Four hundred seven patients received MAC consisting of TBI doses $>10$ Gy or busulfan doses $>8 \mathrm{mg} / \mathrm{kg}$ plus other drugs, and 315 patients underwent RIC including fludarabine in combination with low-dose TBI ( $<2 \mathrm{~Gy}$ ) or busulfan doses $<8 \mathrm{mg} / \mathrm{kg}$. The results showed that NRM was higher after MAC, while RIC transplants were associated with a higher relapse risk, even after adjustment for various factors. There was, however, no difference in 2-year relapse-free and overall survival. The incidences of grades 2-4 acute GvHD and chronic GvHD were also lower after RIC. (Table 2).

Another retrospective EBMT registry study by Martino et al. in MDS patients compared RIC (mainly consisting of fludarabine-busulfan regimens) with standard MAC (mainly TBI-cyclophosphamide or busulfan-cyclophosphamide). ${ }^{31}$ In multivariate analysis, the 3-year incidence of relapse was significantly higher in the RIC group, with a risk increased by $64 \%$. In contrast, the risk of NRM was significantly decreased by $39 \%$ compared with that in the MAC arm. Acute GvHD was seen more frequently in MAC, while rates of chronic GvHD were comparable. The 3-year estimated progression-free and overall survival rates were similar in both groups. Of note, these findings were also confirmed after long-term follow-up. ${ }^{32}$

Similar conclusions were reached from comparative analyses of unrelated donor transplants. ${ }^{33}$ More stratified comparisons of NMA, RIC, conventional, and so-called hyper-intensive MAC in patients with AML/MDS with $<10 \%$ blasts ${ }^{13}$ showed significant and interesting differences in NRM over time: while the NRM at day 100 was highest for hyper-intensive MAC (22\%) followed by MAC $(11 \%)$ and RIC (4\%) and NMA (0\%), the landmark NRM after day 100 showed the highest NRM rate for NMA $(32 \%)$ followed by RIC (17\%), MAC (14\%) and hyperintensive conditioning $(11 \%)$.

Another large Center for International Blood \& Marrow Transplant Research (CIBMTR) analysis considered 3,731 MAC and 1,448 RIC/NMA procedures performed between 1997 and 2004. The relapse rates were significantly higher in the RIC and NMA groups than in the MAC group, but there was no difference in NRM rates. Adjusted overall survival rates at 5 years were $34 \%$, 33\% and $26 \%$ for MAC, RIC and NMA transplants, respectively. NMA conditioning resulted in inferior disease-free survival and overall survival, but there was no difference in these survival outcomes between RIC and MAC regimens (Table 2)..$^{34}$

In summary, retrospective studies in $\mathrm{AML} / \mathrm{MDS}$ depict a homogeneous landscape of evidence, suggesting increased risk of relapse after RIC and a higher NRM after MAC, while overall survival appeared to be similar comparing both intensities.

\section{Retrospective studies in other diseases}

\section{Other myeloid malignancies}

In chronic phase chronic myeloid leukemia, using CIBMTR information 1,395 allogeneic HSCT recipients aged 18-60 years were evaluated in the era of tyrosine kinase inhibition (2007-2014). ${ }^{35}$ No significant differences between conditioning intensities were detected in multivariable analysis with respect to leukemia-free survival and NRM. Regarding relapse, the RIC group showed a higher risk of early relapse, and the incidence of chronic GvHD was lower with RIC than with MAC.

In myelofibrosis, an EBMT analysis using data from 2000-2014 showed comparable incidences of NRM between the intensity groups and slightly increased relapse incidence for RIC, with rates at 1 and 5 years of, respectively, $14 \%$ and $23 \%$ for RIC, and $11 \%$ and $20 \%$ for MAC. No significant difference in 5-year overall survival was seen between the two arms.

\section{Lymphoid malignancies}

In acute lymphoblastic leukemia, an analysis evaluated the outcomes of 576 adult patients $\geq 45$ years, undergoing HSCT from an HLA-identical sibling in complete remission. ${ }^{37}$ With a median follow-up of 16 months, the 2-year NRM rate was higher in the MAC group and relapse was increased following RIC. In multivariate analysis, the type of conditioning regimen was not significantly associated with survival.

Table 2. Selected retrospective registry comparisons of conditioning intensity in acute myeloid leukemia/myelodysplastic syndromes.

\begin{tabular}{|c|c|c|c|c|c|c|c|}
\hline Trial & Registry & Population & N & \multicolumn{4}{|c|}{$\%$, RlC vs. MAC (P) } \\
\hline Aoudjhane et al. ${ }^{30}$ & EBMT & $\begin{array}{c}\text { AML } \\
\text { Age }>50 y\end{array}$ & 722 & $\begin{array}{l}40 \text { vs. } 47 \\
\text { (ns) }\end{array}$ & $\begin{array}{l}41 \text { vs. } 24 \\
(<0.01)\end{array}$ & $\begin{array}{l}18 \text { vs. } 32 \\
(<0.01)\end{array}$ & $\begin{array}{l}44 \text { vs. } 46 \\
\text { (ns) }\end{array}$ \\
\hline Martino et al. ${ }^{13}$ & EBMT & $\begin{array}{c}\text { AML/MDS } \\
\text { Blasts }<10 \%\end{array}$ & 878 & $\begin{array}{l}48 \text { vs. } 54 \\
\text { (ns) }\end{array}$ & $\begin{array}{c}34 \text { vs. } 24 \\
(0.01)\end{array}$ & $\begin{array}{c}18 \text { us. } 22 \\
\text { (ns) }\end{array}$ & $\begin{array}{c}53 \text { vs. } 56 \\
\text { (ns) }\end{array}$ \\
\hline Luger et al..$^{34}$ & CIBMTR & $\begin{array}{l}\text { AML/MDS } \\
\text { Age } 18-69 \text { y }\end{array}$ & 5179 & $\begin{array}{c}30 \text { vs } 33 \\
(\mathrm{~ns})\end{array}$ & $\begin{array}{c}40 \text { us } 32^{*} \\
(<0.01)\end{array}$ & $\begin{array}{c}29 \text { us } 29 \\
\text { (ns) }\end{array}$ & $\begin{array}{c}33 \text { vs } 34 \\
\text { (ns) }\end{array}$ \\
\hline
\end{tabular}

RIC: reduced intensity conditioning; EBMT: European Society for Blood and Marrow Transplantation; CIBMTR: Center for International Blood \& Marrow Transplant Research; MAC: myeloablative conditioning;AML: acute myeloid leukemia; CML: chronic myeloid leukemia; DLBCL: diffuse large B-cell lymphoma;ALL: acute lymphoblastic leukemia; MM: multiple myeloma; MDS: myelodysplastic syndromes; N: number; LFS: leukemia-free survival; RFS: relapse-free survival; NRM: non-relapse mortality; OS: overall survival; ns: not significant; y: years. *in the RIC arm of the CIBMTR study non-myeloablative conditioning regimens are also included. 
Regarding diffuse large B-cell lymphoma, the CIBMTR analyzed 396 patients, of whom 165 received MAC, 143 RIC, and $88 \mathrm{NMA}^{38}$ NRM was higher after MAC, while relapse incidence was higher after RIC. Survival and GvHD rates did not differ between groups. In patients with relapsed/refractory Hodgkin lymphoma, ${ }^{39} \mathrm{NRM}$ rates were similar and relapse risk was slightly reduced for MAC compared with RIC. Subsequently, survival appeared to be better for recipients of MAC.

In multiple myeloma patients, an analysis from the EBMT (1991-2012) evaluated patients 40-60 years old at the time of HSCT. ${ }^{40}$ At a median follow-up of 54 months, MAC was associated with a higher risk of death than RIC. ${ }^{41}$ Notably, results after 2002 were comparable. The main results of the retrospective analyses for hematologic malignancies other than AML/MDS comparing RIC versus MAC are summarized in Table 3.

\section{Factors which may be helpful in the decision process: balance between the risk of relapse and non-relapse mortality}

Since, in general, compared to a lower intensity conditioning regimen, a higher intensity one is associated with more NRM but less relapse, selecting the optimal intensity of the conditioning regimen requires an appropriate balance between the risk of relapse and NRM (Figure 1). Thus, other disease-, patient-, and transplant-specific risk factors that affect the risk of relapse and NRM should be taken into account. Next we summarize specific factors that may complicate clinical decision-making (Table 4).

\section{Measurable disease status}

Multiple studies, mainly in acute lymphoblastic leukemia and more recently in AML, have investigated the association between the presence of measurable residual disease (MRD) prior to allogeneic HSCT, ${ }^{42}$ showing an increased risk of relapse and death among MRDpositive patients. However, significant between-study heterogeneity was found, underscoring site-specific methodological differences. A recent European LeukemiaNet consensus document identified key clinical and scientific issues in the measurement and application of $\mathrm{MRD}$ in $\mathrm{AML}$, providing guidelines for the current and future use of MRD in clinical practice. ${ }^{43}$

With regards to the conditioning intensity, Walter et al. ${ }^{44}$ showed that MRD status had strong predictive value both in the MAC and NMA settings, with MRD-defined depth of response prior to HSCT being the most important predictor of outcome. Conversion from MRD-positivity before HSCT to MRD-negativity after MAC was shown to not substantially improve the incidence of relapse or survival rate..$^{45}$

Table 3. Selected retrospective registry comparisons of conditioning intensity in other hematologic malignancies.

\begin{tabular}{|c|c|c|c|c|c|c|c|}
\hline Trial & Registry & Population & N & LFS/RFS & Relapse & NRM & OS \\
\hline & & & & & $\%$, RIC V & $(P)$ & \\
\hline McLornan et al..$^{36}$ & EBMT & $\begin{array}{c}\text { MF } \\
\text { Age } 18-74 \text { y }\end{array}$ & 2224 & $\begin{array}{c}26 \text { vs. } 32 \\
(0.001)^{*}\end{array}$ & $\begin{array}{c}20 \text { vs. } 23 \\
(0.08)\end{array}$ & $\begin{array}{c}34 \text { vs. } 34 \\
\text { (ns) }\end{array}$ & $\begin{array}{l}51 \text { vs. } 53 \\
\text { (ns) }\end{array}$ \\
\hline Chhabra et al..$^{35}$ & CIBMTR & $\begin{array}{c}\text { CML } \\
\text { Agel8-60y }\end{array}$ & 1395 & $\begin{array}{l}43 \text { vs. } 44 \\
\text { (ns) }\end{array}$ & $\begin{array}{l}25 \text { vs. } 26 \\
\text { (ns) }\end{array}$ & $\begin{array}{c}29 \text { us. } 32 \\
\text { (ns) }\end{array}$ & $\begin{array}{c}53 \text { vs. } 53 \\
\text { (ns) }\end{array}$ \\
\hline Bacher et $a l^{38}$ & CIBMTR & $\begin{array}{c}\text { DLBCL } \\
\text { Age } 18-69 \text { y }\end{array}$ & 396 & $\begin{array}{c}15 \text { vs. } 18 \\
\text { (ns) }\end{array}$ & $\begin{array}{c}38 \text { vs. } 26 \\
(0.03)\end{array}$ & $\begin{array}{c}47 \text { vs. } 56 \\
(0.01)\end{array}$ & $\begin{array}{c}20 \text { vs. } 18 \\
\text { (ns) }\end{array}$ \\
\hline Genadieva-Stravrik et al..$^{39}$ & EBMT & $\begin{array}{c}\mathrm{rrHL} \\
\text { Age } 25-40 \mathrm{y}\end{array}$ & 312 & $\begin{array}{c}36 \text { vs. } 48 \\
(0.07)\end{array}$ & $\begin{array}{l}60 \text { us. } 50 \\
\text { (ns) }\end{array}$ & $\begin{array}{l}12 \text { vs. } 13 \\
\text { (ns) }\end{array}$ & $\begin{array}{c}62 \text { vs. } 73 \\
\text { (ns) }\end{array}$ \\
\hline Mohty et al..$^{37}$ & EBMT & $\begin{array}{c}\text { ALL } \\
\text { Age } \geq 45 \text { y }\end{array}$ & 576 & $\begin{array}{c}32 \text { vs. } 38 \\
(0.07)\end{array}$ & $\begin{array}{l}47 \text { vs. } 31 \\
(<0.01)\end{array}$ & $\begin{array}{c}21 \text { vs. } 29 \\
(0.03)\end{array}$ & $\begin{array}{c}48 \text { vs. } 45 \\
\text { (ns) }\end{array}$ \\
\hline Crawley et al..$^{41}$ & EBMT & $\begin{array}{c}\text { MM } \\
\text { Age } 29-66 \text { y }\end{array}$ & 516 & $\begin{array}{c}19 \text { vs. } 34 \\
(<0.01)\end{array}$ & $\begin{array}{r}54 \text { us. } 27 \\
(<0.01)\end{array}$ & $\begin{array}{c}24 \text { vs. } 37 \\
(<0.01)\end{array}$ & $\begin{array}{c}39 \text { vs. } 51 \\
\text { (ns) }\end{array}$ \\
\hline
\end{tabular}

RIC: reduced intensity conditioning; EBMT: European Society for Blood and Marrow Transplantation; CIBMTR: Center for International Blood \& Marrow Transplant Research; MAC: myeloablative conditioning; AML: acute myeloid leukemia; CML: chronic myeloid leukemia; DLBCL: diffuse large B-cell lymphoma;ALL: acute lymphoblastic leukemia; MM: multiple myeloma; MDS: myelodysplastic syndromes; N: number; LFS: leukemia-free survival; RFS: relapse-free survival; NRM: non-relapse mortality; OS: overall survival; ns: not significant; y: years. *Unadjusted graft-versus-host disease/relapse-free survival at 5 years.

Conditioning regimen

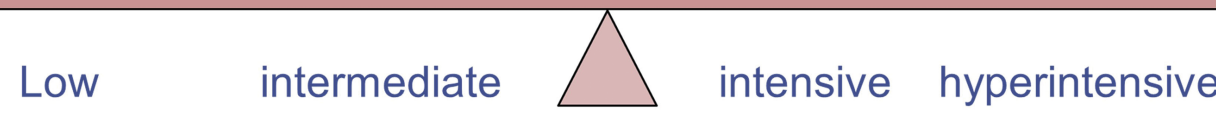

risk of NRM

risk of relapse

Figure 1. The balance between risk for non-relapse mortality and risk for relapse when choosing conditioning intensity. 
In a comparison of conditioning regimen intensities, a correlative analysis was performed of ultra-deep DNA sequencing of blood samples from patients treated in the BMT-CTN trial. ${ }^{26,46}$ Of the 218 AML patients, 190 patients had blood samples collected prior to HSCT, which were analyzed using a 13-gene, targeted error-corrected, next-generation sequencing panel for the presence of genomic MRD. Among these patients, $63 \%$ randomized to RIC and $68 \%$ randomized to MAC had evidence of MRD by detection of one or more of the tested genes. It should, however, be pointed out that current European LeukemiaNet recommendations do not support mutations such as FLT3-ITD, NRAS, DNMT3A, or $A S X L 1$, and expression levels of EVI1 as single MRD markers. ${ }^{43}$ Instead, these markers are suggested to be useful when used in combination with a second MRD marker.

Among MRD-positive patients in this analysis, ${ }^{46}$ outcomes were dismal for those given RIC, with a 3-year incidence of relapse of $67 \%$ versus $19 \%$ in the MAC group. After adjusting for disease risk and donor group, RIC was associated with a significantly increased risk of relapse and decreased survival in MRD-positive patients, when compared to MAC. However, the 3-year NRM rate was higher in those who underwent MAC (27\%) than in those who received RIC (9\%), and this difference was not affected by MRD status. Furthermore, overall survival was comparable in the two groups among patients who were MRD-negative.

In line with these results, an EBMT analysis of 2,292 AML patients in first complete remission showed that less intensive conditioning was only inferior to MAC for patients $<50$ years old who were MRD-positive, showing higher relapse and lower survival rates. ${ }^{47}$ Irrespective of age, conditioning intensities were associated with similar outcomes in patients who were MRD-negative. This analysis also revealed the better caption of the "real world" using our proposed balanced conditioning approach, because RIC/MAC groups shared the same heterogeneous spectrum of regimens used, with only different distributions of certain regimens. A significant caveat regarding this study is that the MRD methodology and allocation were determined by individual participating centers, utilizing molecular and/or immunophenotyping criteria. An earlier CIBMTR analysis of 197 patients with acute lymphoblastic leukemia showed that MRDpositive patients had a higher risk of relapse with RIC, ${ }^{48}$ but MRD-negative patients who also received tyrosine kinase inhibitor therapy before HSCT had superior survival after RIC compared to a similar population after MAC. After multivariable adjustment, RIC reduced NRM but increased relapse risk.

In light of these results that suggest benefits of more intensive conditioning primarily for some or all AML patients who were MRD-positive prior to HSCT, a recent analysis suggested that MAC should also be considered for MRD-negative AML patients if tolerated. ${ }^{49}$

In an analysis of 287 patients with $M D S,{ }^{50}$ of whom one quarter had $>5 \%$ marrow blasts and more than a half were MRD-positive at HSCT, as determined by multiparameter flow cytometry and cytogenetics on marrow aspirates, it was found that the risk of overall mortality was higher with lower intensity retimens than with higher intensity regimens among the $M R D$-positive patients. On the other hand, MRD-negative patients had similar risks of mortali-
Table 4. Risk factors influencing treatment failure (relapse or NRM) after allogeneic HSCT.

Disease-specific factors

Advanced disease status

Unfavorable cytogenetics/molecular genetics

Susceptibility to GVL-effect

Patient-specific risk factors

Age

Performance status

Comorbidities

relapse $>$ NRM

relapse $>$ NRM

relapse $>$ NRM

Transplant-specific risk factors

MRD positivity

HLA disparity

CMV incompatibility

Center effect (JACIE accredited)

NRM $>$ relapse

$\mathrm{NRM}>$ relapse $\mathrm{NRM}>$ relapse

NRM, non-relapse mortality; HSCT, hematopoietic stem cell transplantation; GVL, graft-versusleukemia effect; MRD, measurable residual disease; CMV, cytomegalovirus; JACIE, Joint Accreditation Committee ISCT-Europe \& EBMT.

ty. The main reason for mortality after lower intensity conditioning in MRD-positive patients was relapse.

Evidence from comparison of conditioning regimens of different intensities according to MRD status in AML is still based on retrospective or post-hoc analyses including heterogeneous use of regimens for each group. Current signals point to a benefit for more intensive approaches in MRD-positive AML patients but the increased risk of NRM needs to be considered. In addition, other factors such as donor selection or graft type may further affect MRD-related outcomes. For example, one retrospective analysis suggested that pre-HSCT MRD-positive patients receiving cord blood as the source of stem cells had a reduced incidence of relapse. in comparison with those receiving transplants from matched unrelated donors and even better survival than those given grafts from mismatched unrelated donors. ${ }^{51}$ Another study reported better outcome after haploidentical HSCT in comparison to HLAidentical sibling transplants in MRD-positive AML patients. $^{52}$

\section{Disease risk}

The evidence regarding the impact of conditioning intensity on different disease risk index (DRI) groups ${ }^{53,54}$ is still limited to some retrospective analyses. One analysis evaluated $380 \mathrm{AML} / \mathrm{MDS}$ patients with either high/very high or low/intermediate DRI. ${ }^{55}$ Among patients with high/very high DRI, there was no difference in outcome between the RIC and MAC groups. For low/intermediate risk DRI, recipients of MAC showed better 3-year overall survival (69\% vs. $57 \%$ ), disease-free survival ( $65 \%$ vs. $51 \%$ ), and a decreased incidence of relapse (17\% vs. 32\%) but similar, slightly increased NRM (19\% vs. 17\%). Except for overall survival, which was not significantly different in multivariable analysis, results for the remaining outcomes were confirmed after multivariable adjustment. In a larger, very recent CIBMTR analysis, MAC resulted in an improved survival in comparison to RIC in AML/MDS patients 40 to 65 years old with low/intermediate risk DRI, but similar clinical benefit to RIC despite higher risk of relapse in patients with high/very high risk DRI. ${ }^{56}$

In conclusion, compared with RIC, MAC may be associated with improved outcomes among patients with low/intermediate DRI, while no benefit has been noted for any intensity among those in high/very high DRI groups. 


\section{Transplant risk score}

Several studies have been published to further aid physicians in balancing the risks and benefits of HSCT for patients. The EBMT transplantation risk score ${ }^{57}$ initially established for chronic myeloid leukemia, has now been expanded and validated to assess post-transplant risk for multiple hematologic disorders that can be treated with a transplant. The risk score includes: the patient's age class $(<20,20-40$, or $>40$ years), disease stage (early, intermediate, or advanced), donor type (HLA-identical sibling or unrelated donor), and donor-recipient sex match/mismatch (specifically, an increased score for a male recipient with female donor). The score held for all acquired hematologic disorders (score 0-5) and was independent of the HSCT procedure itself. This risk scheme does not specifically consider comorbidities (see below), and notably places all patients $>40$ years in a high-risk category. Importantly, the EBMT risk score was independently valid, irrespective of the intensity of the conditioning.

In line with these findings, an EBMT mega-file analysis showed that patients' pre-HSCT risk factors determine survival,${ }^{58}$ independently of conditioning intensities, suggesting that outcomes may be improved more effectively through better identifying patients with their individual pre-HSCT characteristics.

In summary, the recent increased efforts will shape future research to establish more individualized risk models for predicting outcome after HSCT in several diseases, irrespective of conditioning intensity. ${ }^{59-62}$

\section{Genetic risk}

The Japanese Society of Hematopoietic Stem Cell Transplantation reported a significant survival benefit from MAC versus RIC in 840 AML patients with poor cytogenetics, irrespective of subgroup analysis for age $<60$ years or high comorbidity index. ${ }^{63}$ In contrast, EBMT studies failed to show any survival benefit of either type of conditioning regimen in patients with cytogenetically poor-risk $\mathrm{AML}^{64,65}$ One such study with AML patients 40-60 years old in first complete remssion, stratified according to cytogenetic risk, found better survival with RIC in low-risk patients but not in the intermediate- or poor-risk groups. ${ }^{65}$ In the latter groups, relapse incidence was lower with MAC, but NRM was higher with MAC in all cytogenetic risk groups. The analysis concluded that in patients 40-60 years old, MAC had no significant advantage. Bornhäuser et al. also reported no difference between MAC and RIC for intermediateand high-risk AML patients in a prospective randomized trial. ${ }^{16}$

Another very recent study in MDS showed that the adverse impact of shorter telomeres on NRM was more frequently observed in patients receiving more intensive conditioning and was associated with the development of GvHD. ${ }^{66}$ Thus, strategies in MDS patients with shorter telomere length may focus on minimizing toxicity and reducing conditioning intensity.

\section{Performance status, comorbidities and age}

There is conflicting evidence regarding the association of conditioning intensity and comorbidities. As described above, the study by Rambaldi et al. showed significantly reduced NRM after busulfan-fludarabine conditioning compared with busulfan-cyclophosphamide conditioning in patients with a comorbidity index $>2 .{ }^{20} \mathrm{~A}$ recent analysis in patients $\geq 50$ years old with Philadelphia-positive acute lymphoblastic leukemia who received tyrosine kinase inhibitor therapy before HSCT and who achieved MRDnegativity showed similar outcomes after RIC or MAC, with subgroup analyses suggesting better outcomes for RIC in patients with a poor performance status or a high HCT-Comorbidity Index. ${ }^{68,69}$ In contrast, the above mentioned Japanese study in patients with cytogenetically poor-risk AML and first complete remission showed an association with better outcomes for $\mathrm{MAC}{ }^{63}$ irrespective of subgroup analysis for patients $<60$ years old or high HCT-Comorbidity Index.

A single-center experience including 875 adults highlights both the pitfalls of arbitrary dichotomization of conditioning intensity and the value of patient-specific balanced evaluations. ${ }^{70}$ The following were classified as RIC: fludarabine $150 \mathrm{mg} / \mathrm{m}^{2}$ with busulfan $6.4 \mathrm{mg} / \mathrm{kg}$; fludarabine $150 \mathrm{mg} / \mathrm{m}^{2}$ with treosulfan $30 \mathrm{~g} / \mathrm{m}^{2}$; and fludarabine $150 \mathrm{mg} / \mathrm{m}^{2}$ with melphalan $100-140 \mathrm{mg} / \mathrm{m}^{2}$. With respect to specific comorbidities in the overall population, which varied widely across regimens, renal dysfunction, hypoalbuminemia, and severe hepatic disease were associated with worse NRM. Notably, the risk was not associated with intensity as classified. Instead, outcome was associated with regimen-specific profiles, showing increased NRM for fludarabine-busulfan in patients with cardiac disease, and for fludarabine-melphalan and fludarabine-treosulfan in patients with severe pulmonary disease and a pre-existing infection. The HCT-Comorbidity Index was only associated with worse outcome in patients receiving fludarabine-melphalan conditioning but not in those given other regimens.

With respect to RIC versus MAC, several analyses showed similar outcomes in patients $\geq 50$ years old. ${ }^{47,71}$ Of note, generally, patients receiving RIC are older by a median of 10 years. ${ }^{2}$ For the evaluation of less intensive conditioning, a retrospective analysis compared the efficacy of RIC in MDS patients $>50$ years, analyzing patients $<65$ or $\geq 65$ years at HSCT separately. Subsequently, in patients $<65$ years, NMA conditioning was associated with higher NRM and shorter survival, while the cumulative incidence of relapse was similar in both the RIC and NMA groups.

The EBMT recently analyzed the outcome of AML patients with reduced performance status according to the Karnofsky performance status of $\leq 80 \%$. Patients with a Karnofsky performance status of $80 \%$ benefited more from MAC, while patients with a performance status $<80 \%$ benefited more from RIC. ${ }^{73}$

In conclusion, simple recommendation of RIC/NMA for older unfit patients or MAC for young and fit ones is not reflected by current evidence. Neither age nor comorbidities are associated with significantly different outcomes for these categorizations. ${ }^{74,75}$ Ultimately, only patients with exceptionally limiting comorbidities/performance may experience different outcomes.

\section{Infections and late effects}

Presumably, less intensive conditioning may lead to reduced rates of infection. However, published evidence on this issue remains limited. Early investigations suggested that RIC may decrease the risk of dying from an opportunistic infection, reducing the frequency of cytomegalovirus infection/disease..$^{8}$ In a recent CIBMTR analysis of 1,755 AML patients $\geq 40$ years old, although absolute numbers of patients with $\geq 1$ infection were not different in the RIC/NMA (58\%) and MAC (61\%) groups, 
the median time to initial infection after MAC occurred earlier, at a median of 15 versus 21 days. ${ }^{77}$ Patients receiving MAC were more likely to experience $\geq 1$ bacterial infection, whereas $\geq 1$ viral infection was more prevalent among those receiving RIC/NMA. Another recent smaller analysis regarding mucositis found infections were less frequent after less intensive conditioning, with the rate being lowest after fludarabine-treosulfan conditioning. ${ }^{78}$

Evaluations regarding long-term effects of different intensity conditioning regimens are scarce. One study showed similar long-term leukemia-free survival and GvHD-free/relapse-free survival at 10 years for RIC and MAC, with most events occurring within the first 2 years after allogeneic HSCT. ${ }^{79}$ Relapse was the major cause of late death in both groups; while NRM and especially chronic GvHD as well as second cancers were more frequent causes of late death after MAC.

\section{Graft-versus-host disease}

Prospective and retrospective comparisons show that relapse is the major cause of death in RIC patients while most MAC patients die from GvHD. This led to the concept of influencing risk of relapse and GvHD to improve outcomes for any given conditioning intensity. ${ }^{80}$ Regarding the latter, the use of post-HSCT cyclophosphamide significantly reduced the risk of GvHD and was associated with better outcomes when used in haploidentical HSCT, at least compared with transplants from mismatched unrelated donors. ${ }^{81}$ In view of this consistent effect of post-HSCT cyclophosphamide, no significant differences according to conditioning intensity in haploidentical transplants were found after meta-regression analyse ${ }^{81}$ and in two large registry analyses ${ }^{82,83}$ So far, it has not been possible to confirm the hypothesis of an association between reduced GvHD after post-HSCT cyclophosphamide and better survival in patients treated with MAC regimens, but comparisons still lack stringent control and assessments in specific donor settings. Here, it is important to underscore the complex interplay of GvHD and risk of relapse with the type of disease or tumor burden, including phenomena that are not yet fully clarified. ${ }^{84}$ In acute lymphoblastic leukemia and BCR-ABL-negative myeloproliferative neoplasms there are similar and obvious correlations between the occurrence of GvHD and risk of relapse when compared with chronic myeloid leukemia, and in MDS and lymphoproliferative disorders there are intermediate correlations between GvHD and relapse risk. Only in AML and plasma cell disorders is GvHD associated with only modest reductions in relapse risk.

\section{Maintenance therapy}

A more personalized approach might incorporate posttransplant strategies to prevent relapse..$^{85-87}$ There is accumulating evidence regarding the efficacy of post-HSCT maintenance therapy with tyrosine kinase inhibitors in AML, specifically for patients with FLT3-ITD mutations. Two prospective studies showed that sorafenib maintenance was associated with significantly better relapse and relapse-free survival outcomes. ${ }^{88,89}$ In the Chinese study all patients were given MAC, ${ }^{88}$ while $58 \%$ of patients in the German study received sorafenib and underwent RIC $\mathrm{HSCT}^{89}$ no stratified comparisons according to conditioning intensity were conducted within this latter study. Limited indirect comparison of the two studies suggest at least comparable outcomes in both, with 2 -year survival rates in the sorafenib arm of $82 \%$ in the Chinese study and $90 \%$ in the German study. Whether the impressive effect of maintenance on relapse, with a $60 \%$ risk reduction, may broaden the utility of less intensive conditioning, is yet to be determined.

\section{Summary}

The answer to "when and for whom" with respect to HSCT conditioning intensity is complex, individualized, and constantly evolving. Apart from factors such as pretreatment, disease risk, donor source, GvHD prophylaxis, and maintenance strategies, the conditioning regimen is only one factor affecting the risk of treatment failure through relapse or NRM after allogeneic HSCT. As of 2021, the traditional, simplified section of a conditioning regimen between RIC and MAC is no longer appropriate because it significantly underestimates the complexity of currently used regimens with respect to toxicity. Updated categorizations from the EBMT ${ }^{15}$ are one step in the right direction but still provide only modest improvements in facilitating decision-making, considering all outcomes. A critical individual balance between the risk of NRM and the risk of relapse must be inclluded in a personalized medicine approach. These individual and continuous considerations may include diverse factors such as disease burden, MRD status and other disease-specific, patient-specific, and transplant-specific risk factors. Furthermore, recent advances in the incorporation of toxicity-reduced conditioning regimens (e.g., treosulfan) and improvements in relapse reduction by including maintenance strategies, as well as immunotherapy approaches after allogeneic HSCT may further refine considerations regarding conditioning intensity, steering towards the use of less intensive and toxic regimens in the future.

\section{Discosures}

No conflicts of interest to disclose.

\section{Contributions}

NG and NK drafted the manuscript and approved the final version.

\section{References}

1. Gyurkocza B, Sandmaier BM. Conditioning regimens for hematopoietic cell transplantation: one size does not fit all. Blood. 2014;124(3):344-353.

2. Giralt S, Ballen K, Rizzo D, et al. Reducedintensity conditioning regimen workshop: defining the dose spectrum. Report of a workshop convened by the Center for International Blood and Marrow Transplant
Research. Biol Blood Marrow Transplant. 2009;15(3):367-369.

3. Champlin R, Khouri I, Kornblau S, Molldrem J, Giralt S. Reinventing bone marrow transplantation: reducing toxicity using nonmyeloablative, preparative regimens and induction of graft-versus-malignancy. Curr Opin Oncol. 1999;11(2):87-95.

4. Bacigalupo A, Ballen K, Rizzo D, et al. Defining the intensity of conditioning regimens: working definitions. Biol Blood
Marrow Transplant. 2009;15(12):1628-1633. 5. Bacigalupo A. Third EBMT/AMGEN Workshop on reduced-intensity conditioning allogeneic haemopoietic stem cell transplants (RIC-HSCT), and panel consensus. Bone Marrow Transplant. 2004;33(7):691696

6. Bacigalupo A. Second EBMT Workshop on reduced intensity allogeneic hemopoietic stem cell transplants (RI-HSCT). Bone Marrow Transplant. 2002;29(3):191-195. 
7. Bacigalupo A. Hematopoietic stem cell transplants after reduced intensity conditioning regimen (RI-HSCT): report of a workshop of the European Group for Blood and Marrow Transplantation (EBMT). Bone Marrow Transplant. 2000;25(8):803-805.

8. Kolb H-J, Schmid C. The FLAMSA conceptpast and future. Ann Hematol. 2020;99(9): 1979-1988.

9. Schmid C, Schleuning M, Ledderose G, Tischer J, Kolb H-J. Sequential regimen of chemotherapy, reduced-intensity conditioning for allogeneic stem-cell transplantation, and prophylactic donor lymphocyte transfusion in high-risk acute myeloid leukemia and myelodysplastic syndrome. I Clin Oncol. 2005;23(24):5675-5687.

10. Bacigalupo A, Raiola AM, Lamparelli T, et al. Thiotepa-based reduced intensity conditioning regimen: a 10 year follow up. Bone Marrow Transplant. 2007;40(11):1091-1093.

11. Langenhorst JB, van Kesteren C, van Maarseveen EM, et al. Fludarabine exposure in the conditioning prior to allogeneic hematopoietic cell transplantation predicts outcomes. Blood Adv. 2019;3(14):21792187.

12. Marks R, Potthoff K, Hahn J, et al. Reducedtoxicity conditioning with fludarabine, $\mathrm{BCNU}$, and melphalan in allogeneic hematopoietic cell transplantation: particular activity against advanced hematologic malignancies. Blood. 2008;112(2):415-425.

13. Martino R, Wreede L de, Fiocco M, et al. Comparison of conditioning regimens of various intensities for allogeneic hematopoietic SCT using HLA-identical sibling donors in AML and MDS with $<10 \%$ BM blasts: a report from EBMT. Bone Marrow Transplant. 2013;48(6):761-770.

14. Craddock C, Jackson A, Loke J, et al. Augmented reduced-intensity regimen does not improve postallogeneic transplant outcomes in acute myeloid leukemia. J Clin Oncol. 2021;39(7):768-778.

15. Spyridonidis A, Labopin M, Savani BN, et al. Redefining and measuring transplant conditioning intensity in current era: a study in acute myeloid leukemia patients. Bone Marrow Transplant. 2020;55(6):1114-1125.

16. Bornhäuser M, Kienast J, Trenschel R, et al. Reduced-intensity conditioning versus standard conditioning before allogeneic haemopoietic cell transplantation in patients with acute myeloid leukaemia in first complete remission: a prospective, open-label randomised phase 3 trial. Lancet. Oncol 2012;13(10):1035-1044.

17. Fasslrinner F, Schetelig J, Burchert A, et al. Long-term efficacy of reduced-intensity versus myeloablative conditioning before allogeneic haemopoietic cell transplantation in patients with acute myeloid leukaemia in first complete remission: retrospective follow-up of an open-label, randomised phase 3 trial. Lancet Haematol. 2018;5(4):e161e169.

18. Martino R, Badell I, Brunet S, et al. Highdose busulfan and melphalan before bone marrow transplantation for acute nonlymphoblastic leukemia. Bone Marrow Transplant. 1995;16(2):209-212.

19. Giralt S, Thall PF, Khouri I, et al. Melphalan and purine analog-containing preparative regimens: reduced-intensity conditioning for patients with hematologic malignancies undergoing allogeneic progenitor cell transplantation. Blood. 2001;97(3):631-637.

20. Rambaldi A, Grassi A, Masciulli A, et al. Busulfan plus cyclophosphamide versus busulfan plus fludarabine as a preparative regimen for allogeneic haemopoietic stemcell transplantation in patients with acute myeloid leukaemia: an open-label, multicentre, randomised, phase 3 trial. Lancet Oncol. 2015;16(15):1525-1536.

21. Peccatori J, Mastaglio S, Giglio F, et al. Clofarabine and treosulfan as conditioning for matched related and unrelated hematopoietic stem cell transplantation: results from the Clo3o phase II trial. Biol Blood Marrow Transplant. 2020;26(2):316322.

22. Shimoni A, Hardan I, Shem-Tov N, Rand A Yerushalmi R, Nagler A. Fludarabine and treosulfan: a novel modified myeloablative regimen for allogeneic hematopoietic stem-cell transplantation with effective antileukemia activity in patients with acute myeloid leukemia and myelodysplastic syndromes. Leuk Lymphoma. 2007;48(12):2352-2359.

23. Kröger N, Shimoni A, Zabelina T, et al. Reduced-toxicity conditioning with treosulfan, fludarabine and ATG as preparative regimen for allogeneic stem cell transplantation (alloSCT) in elderly patients with secondary acute myeloid leukemia (sAML) or myelodysplastic syndrome (MDS). Bone Marrow Transplant. 2006:37:339-344.

24. Beelen DW, Trenschel R, Stelljes M, et al. Treosulfan or busulfan plus fludarabine as conditioning treatment before allogeneic haemopoietic stem cell transplantation for older patients with acute myeloid leukaemia or myelodysplastic syndrome (MCFludT.14/L): a randomised, non-inferiority, phase 3 trial. Lancet Haematol. 2020;7(1): e28-e39.

25. Kröger N, Iacobelli S, Franke G-N, et al. Dose-reduced versus standard conditioning followed by allogeneic stem-cell transplantation for patients with myelodysplastic syndrome: a prospective randomized phase III study of the EBMT (RICMAC trial). J Clin Oncol. 2017;35(19):2157-2164.

26. Scott BL, Pasquini MC, Logan BR, et al. Myeloablative versus reduced-Intensity hematopoietic cell transplantation for acute myeloid leukemia and myelodysplastic syndromes. J Clin Oncol. 2017;35(11):1154 1161

27. Blaise D, Tabrizi R, Boher J-M, et al Randomized study of 2 reduced-intensity conditioning strategies for human leukocyte antigen-matched, related allogeneic peripheral blood stem cell transplantation: prospective clinical and socioeconomic evaluation. Cancer. 2013;119(3):602-611.

28. Rashidi A, Meybodi MA, Cao W, et al. Myeloablative versus reduced-intensity hematopoietic cell transplantation in myelodysplastic syndromes: systematic review and meta-analysis. Biol Blood Marrow Transplant. 2020;26(6):e138-e141.

29. Ma S, Shi W, Li Z, et al. Reduced-intensity versus myeloablative conditioning regimens for younger adults with acute myeloid leukemia and myelodysplastic syndrome: systematic review and meta-analysis. Cancer. 2020;11(17):5223-5235

30. Aoudjhane M, Labopin M, Gorin NC, et al. Comparative outcome of reduced intensity and myeloablative conditioning regimen in HLA identical sibling allogeneic haematopoietic stem cell transplantation for patients older than 50 years of age with acute myeloblastic leukaemia: a retrospective survey from the Acute Leukemia Working Party (ALWP) of the European group for Blood and Marrow Transplantation (EBMT). Leukemia. 2005;19 (12):2304-2312.
31. Martino R, Iacobelli S, Brand $\mathrm{R}$, et al Retrospective comparison of reduced-intensity conditioning and conventional highdose conditioning for allogeneic hematopoietic stem cell transplantation using HLAidentical sibling donors in myelodysplastic syndromes. Blood. 2006;108(3):836-846.

32. Martino R, Henseler A, van Lint M, et al. Long-term follow-up of a retrospective comparison of reduced-intensity conditioning and conventional high-dose conditioning for allogeneic transplantation from matched related donors in myelodysplastic syndromes. Bone Marrow Transplant. 2017; 52(8):1107-1112.

33. Ringdén O, Labopin M, Ehninger G, et al Reduced intensity conditioning compared with myeloablative conditioning using unrelated donor transplants in patients with acute myeloid leukemia. J Clin Oncol. 2009;27(27):4570-4577.

34. Luger SM, Ringdén O, Zhang M-J, et al Similar outcomes using myeloablative vs reduced-intensity allogeneic transplant preparative regimens for AML or MDS Bone Marrow Transplant. 2012;47(4):203211

35. Chhabra S, Ahn KW, Hu Z-H, et al Myeloablative vs reduced-intensity conditioning allogeneic hematopoietic cell transplantation for chronic myeloid leukemia. Blood Adv. 2018;2(21):2922-2936.

36. McLornan D, Szydlo R, Koster L, et al Myeloablative and reduced-intensity conditioned allogeneic hematopoietic stem cell transplantation in myelofibrosis: a retrospective study by the Chronic Malignancies Working Party of the European Society for Blood and Marrow Transplantation. Biol Blood Marrow Transplant. 2019;25(11): 2167-2171.

37. Mohty M, Labopin M, Volin L, et al Reduced-intensity versus conventional myeloablative conditioning allogeneic stem cell transplantation for patients with acute lymphoblastic leukemia: a retrospective study from the European Group for Blood and Marrow Transplantation. Blood. 2010;116 (22):4439-4443

38. Bacher U, Klyuchnikov E, Le-Rademacher J, et al. Conditioning regimens for allotransplants for diffuse large B-cell lymphoma: myeloablative or reduced intensity? Blood. 2012;120(20):4256-4262

39. Genadieva-Stavrik S, Boumendil A, Dreger $\mathrm{P}$, et al. Myeloablative versus reduced intensity allogeneic stem cell transplantation for relapsed/refractory Hodgkin's lymphoma in recent years: a retrospective analysis of the Lymphoma Working Party of the European Group for Blood and Marrow Transplantation. Ann Oncol. 2016;27 (12):2251-2257

40. Hayden PJ, Iacobelli S, Pérez-Simón JA, et al. Conditioning-based outcomes after allogeneic transplantation for myeloma following a prior autologous transplant (1991 2012) on behalf of EBMT CMWP. Eur J Haematol. 2020;104(3):181-189.

41. Crawley C, Iacobelli S, Björkstrand B, Apperley JF, Niederwieser D, Gahrton G. Reduced-intensity conditioning for myeloma: lower nonrelapse mortality but higher relapse rates compared with myeloablative conditioning. Blood. 2007;109(8):3588-3594.

42. Buckley SA, Wood BL, Othus $M$, et al. Minimal residual disease prior to allogeneic hematopoietic cell transplantation in acute myeloid leukemia: a meta-analysis. Haematologica. 2017;102(5):865-873.

43. Schuurhuis GJ, Heuser M, Freeman S, et al. 
Minimal/measurable residual disease in AML: a consensus document from the European LeukemiaNet MRD Working Party. Blood. 2018;131(12):1275-1291.

44. Walter RB, Othus M, Burnett AK, et al. Resistance prediction in AML: analysis of 4601 patients from MRC/NCRI, HOVON/SAKK, SWOG and MD Anderson Cancer Center. Leukemia. 2015;29(2):312320

45. Zhou Y, Othus M, Araki D, et al. Pre- and post-transplant quantification of measurable ('minimal') residual disease via multiparameter flow cytometry in adult acute myeloid leukemia. Leukemia. 2016;30(7): 1456-1464.

46. Hourigan CS, Dillon LW, Gui G, et al. Impact of conditioning intensity of allogeneic transplantation for acute myeloid leukemia with genomic evidence of residual disease. J Clin Oncol. 2020;38(12):12731283.

47. Gilleece MH, Labopin M, Yakoub-Agha I, et al. Measurable residual disease, conditioning regimen intensity, and age predict outcome of allogeneic hematopoietic cell transplantation for acute myeloid leukemia in first remission: a registry analysis of 2292 patients by the Acute Leukemia Working Party European Society of Blood and Marrow Transplantation. Am J Hematol. 2018;93(9):1142-1152.

48. Bachanova V, Marks DI, Zhang M-J, et al. $\mathrm{Ph}+\mathrm{ALL}$ patients in first complete remission have similar survival after reduced intensity and myeloablative allogeneic transplantation: impact of tyrosine kinase inhibitor and minimal residual disease. Leukemia. 2014;28(3):658-665

49. Morsink LM, Sandmaier BM, Othus M, et al. Conditioning intensity, pre-transplant flow cytometric measurable residual disease, and outcome in adults with acute myeloid leukemia undergoing allogeneic hematopoietic cell transplantation. Cancers. 2020;12(9):2339

50. Festuccia M, Deeg HJ, Gooley TA, et al. Minimal identifiable disease and the role of conditioning intensity in hematopoietic cell transplantation for myelodysplastic syndrome and acute myelogenous leukemia evolving from myelodysplastic syndrome. Biol Blood Marrow Transplant 2016;22(7): 1227-1233.

51. Milano F, Gooley T, Wood B, et al. Cordblood transplantation in patients with minimal residual disease. $\mathrm{N}$ Engl J Med. 2016;375(10):944-953.

52. Chang Y-J, Wang Y, Liu Y-R, et al. Haploidentical allograft is superior to matched sibling donor allograft in eradicating pre-transplantation minimal residual disease of AML patients as determined by multiparameter flow cytometry: a retrospective and prospective analysis. J Hematol Oncol. 2017;10(1):134.

53. Armand P, Gibson CJ, Cutler C, et al. A disease risk index for patients undergoing allogeneic stem cell transplantation. Blood. 2012;120(4):905-913.

54. Armand P, Kim HT, Logan BR, et al. Validation and refinement of the Disease Risk Index for allogeneic stem cell transplantation. Blood. 2014;123(23):3664-3671.

55. Solh MM, Solomon SR, Morris LE, Zhang X, Holland HK, Bashey A. The dilemma of conditioning intensity: when does myeloablative conditioning improve outcomes for allogeneic hematopoietic cell transplantation. Biol Blood Marrow Transplant. 2019;25 (3):606-612.
56. Bejanyan N, Zhang M, Bo-Subait K. Myeloablative conditioning for allogeneic transplantation results in superior diseasefree survival for acute myeloid leukemia and myelodysplastic syndromes with low/inter mediate, but not high disease risk Index: CIBMTR study. Transplant Cell Ther. 2021;27(1):68.e1-68.e9

57. Gratwohl A. The EBMT risk score. Bone Marrow Transplant. 2012;47(6):749-756

58. Gratwohl A, Duarte R, Snowden JA, et al Pre-transplantation risks and transplanttechniques in haematopoietic stem cell transplantation for acute leukaemia. EClinicalMedicine. 2019;15:33-41.

59. Gagelmann N, Ditschkowski M, Bogdanov $\mathrm{R}$, et al. Comprehensive clinical-molecular transplant scoring system for myelofibrosis undergoing stem cell transplantation. Blood. 2019;133(20):2233-2242.

60. Gagelmann N, Eikema D-J, Stelljes M, et al. Optimized EBMT transplant-specific risk score in myelodysplastic syndromes after allogeneic stem-cell transplantation. Haematologica. 2019;104(5):929-936.

61. Shaffer BC, Ahn KW, Hu Z-H, et al. Scoring system prognostic of outcome in patients undergoing allogeneic hematopoietic cell transplantation for myelodysplastic syndrome. J Clin Oncol. 2016;34(16):1864-1871.

62 . Versluis J, Cornelissen JJ. Risks and benefits in a personalized application of allogeneic transplantation in patients with AML in first CR. Semin Hematol. 2019;56(2):164-170.

63. Konuma T, Kondo T, Mizuno S. Conditioning intensity for allogeneic hematopoietic cell transplantation in acute myeloid leukemia patients with poor-prognosis cytogenetics in first complete remission. Biol Blood Marrow Transplant. 2020;26(3):463-471

64. Versluis J, Labopin M, Ruggeri A, et al Alternative donors for allogeneic hematopoietic stem cell transplantation in poor-risk AML in CR1. Blood Adv. 2017; (7):477-485

65. Passweg JR, Labopin M, Cornelissen J, et al Conditioning intensity in middle-aged patients with AML in first CR: no advantage for myeloablative regimens irrespective of the risk group-an observational analysis by the Acute Leukemia Working Party of the EBMT. Bone Marrow Transplant. 2015;50 (8):1063-1068.

66. Myllymäki M, Redd R, Reilly $\mathrm{CR}$, et al. Short telomere length predicts nonrelapse mortality after stem cell transplantation for myelodysplastic syndrome. Blood. 2020;136 (26):3070-3081.

67. Akahoshi Y, Nishiwaki S, Arai Y, et al. Reduced-intensity conditioning is a reasonable alternative for Philadelphia chromosome-positive acute lymphoblastic leukemia among elderly patients who have achieved negative minimal residual disease: a report from the Adult Acute Lymphoblastic Leukemia Working Group of the JSHCT. Bone Marrow Transplant. 2020;55(7):1317-1325.

68. Sorror ML, Maris MB, Storb R, et al. Hematopoietic cell transplantation (HCT) specific comorbidity index: a new tool for risk assessment before allogeneic HCT. Blood. 2005;106(8):2912-2919.

69. Mor V, Laliberte L, Morris JN, Wiemann M. The Karnofsky Performance Status Scale. An examination of its reliability and validity in a research setting. Cancer. 1984;53(9):20022007.

70. Fein JA, Shimoni A, Labopin M, et al. The impact of individual comorbidities on non- relapse mortality following allogeneic hematopoietic stem cell transplantation. Leukemia. 2018;32(8):1787-1794.

71. Gilleece MH, Labopin M, Savani BN, et al. Allogeneic haemopoietic transplantation for acute myeloid leukaemia in second complete remission: a registry report by the Acute Leukaemia Working Party of the EBMT. Leukemia. 2020;34(1):87-99.

72. Sengsayadeth S, Gatwood KS, Boumendil A, et al. Conditioning intensity in secondary AML with prior myelodysplastic syndrome/myeloproliferative disorders: an EBMT ALWP study. Blood Adv. 2018;2(16) 2127-2135.

73. Saraceni F, Labopin M, Forcade E, et al. Allogeneic stem cell transplant in patient with acute myeloid leukemia and karnofsky performance status score less than or equal to $80 \%$ : a study from the Acute Leukemia Working Party of the European Society for Blood and Marrow Transplantation (EBMT). Cancer Med. 2021;10(1):23-33.

74. Sorror ML, Estey E. Allogeneic hematopoietic cell transplantation for acute myeloid leukemia in older adults. Hematology Am Soc Hematol Educ Program. 2014;2014:2133

75. Castagna L, Fürst S, Marchetti N, et al Retrospective analysis of common scoring systems and outcome in patients older than 60 years treated with reduced-intensity conditioning regimen and alloSCT. Bone Marrow Transplant. 2011;46(7): 1000-1005.

76. Martino R, Caballero MD, Canals C, et al. Reduced-intensity conditioning reduces the risk of severe infections after allogeneic peripheral blood stem cell transplantation. Bone Marrow Transplant. 2001;28(4):341 347

77. Ustun C, Kim S, Chen M, et al. Increased overall and bacterial infections following myeloablative allogeneic HCT for patients with AML in CR1. Blood Adv. 2019;3(17): 2525-2536

78. Shouval R, Kouniavski E, Fein J, et al. Risk factors and implications of oral mucositis in recipients of allogeneic hematopoietic stem cell transplantation. Eur J Haematol 2019;103(4):402-409.

79. Shimoni A, Labopin M, Savani B, et al. Long-term survival and late events after allogeneic stem cell transplantation from HLA matched siblings for acute myeloid leukemia with myeloablative compared to reduced-intensity conditioning: a report on behalf of the acute leukemia working party of European group for blood and marrow transplantation. J Hematol Oncol. 2016;9 (1):118.

80. Storb R, Gyurkocza B, Storer BE, et al. Graftversus-host disease and graft-versus-tumor effects after allogeneic hematopoietic cell transplantation. J Clin Oncol. 2013;31(12) 1530-1538.

81. Gagelmann N, Bacigalupo A, Rambaldi A, et al. Haploidentical stem cell transplantation with posttransplant cyclophosphamide therapy vs other donor transplantations in adult with hematologic cancers: a systematic review and meta-analysis. JAMA Oncol. 2019;5(12):1739-1748.

82. Brissot E, Labopin M, Ehninger G, et al Haploidentical versus unrelated allogeneic stem cell transplantation for relapsed/refractory acute myeloid leukemia: a report on 1578 patients from the Acute Leukemia Working Party of the EBMT. Haematologica. 2019;104(3):524-532.

83. Ciurea SO, Zhang M-J, Bacigalupo AA, et al. 
Haploidentical transplant with posttransplant cyclophosphamide vs matched unrelated donor transplant for acute myeloid leukemia. Blood. 2015;126(8):1033-1040.

84. Stern M, Wreede LC de, Brand R, et al. Sensitivity of hematological malignancies to graft-versus-host effects: an EBMT megafile analysis. Leukemia. 2014;28(11):2235-2240.

85. Gökbuget N, Canaani J, Nagler A, Bishop M, Kröger N, Avigan D. Prevention and treatment of relapse after stem cell transplantation with immunotherapy. Bone Marrow Transplant. 2018;53(6):664-672.

86. Falkenburg F, Ruggiero E, Bonini C, et al. Prevention and treatment of relapse after stem cell transplantation by cellular therapies. Bone Marrow Transplant. 2019;54(1): 26-34.

87.Zeiser R, Beelen DW, Bethge W, et al. Biology-driven approaches to prevent and treat relapse of myeloid neoplasia after allogeneic hematopoietic stem cell transplantation. Biol Blood Marrow Transplant. 2019;25(4):e128-e140.

88. Xuan L, Wang Y, Huang F, et al. Sorafenib maintenance in patients with FLT3-ITD acute myeloid leukaemia undergoing allogeneic haematopoietic stem-cell transplantation: an open-label, multicentre, randomised phase 3 trial. Lancet Oncol. 2020;21(9):1201
1212.

89. Burchert A, Bug G, Fritz LV, et al. Sorafenib maintenance after allogeneic hematopoietic stem cell transplantation for acute myeloid leukemia with FLT3-internal tandem duplication mutation (SORMAIN). J Clin Oncol. 2020;38(26):2993-3002.

90. Ringdén O, Erkers T, Aschan J, et al. A prospective randomized toxicity study to compare reduced-intensity and myeloablative conditioning in patients with myeloid leukaemia undergoing allogeneic haematopoietic stem cell transplantation. Intern Med. 2013;274(2):153-162. 